\title{
Féeries
}

Études sur le conte merveilleux, XVII ${ }^{\mathrm{e}} \mathrm{XIX} \mathrm{X}^{\mathrm{e}}$ siècle

$17 \mid 2021$

Contes en couleur

\section{L'Épanchement du conte dans la littérature}

Textes réunis et présentés par Christiane Connan-Pintado, Pascale Auraix-Jonchière et Gilles Béhotéguy, Bordeaux, Presses Universitaires de Bordeaux, coll. « Modernités », $n^{\circ}$ 43, 2018, 284 p.

Jean Mainil

\section{OpenEdition}

Journals

Édition électronique

URL : https://journals.openedition.org/feeries/4109

DOI : 10.4000/feeries.4109

ISSN : 1957-7753

Éditeur

UGA Éditions/Université Grenoble Alpes

Édition imprimée

ISBN : 978-2-37747-327-4

ISSN : $1766-2842$

Référence électronique

Jean Mainil, «L'Épanchement du conte dans la littérature », Féeries [En ligne], 17 | 2021, mis en ligne le 17 décembre 2021, consulté le 14 janvier 2023. URL : http://journals.openedition.org/feeries/4109 ; DOI : https://doi.org/10.4000/feeries.4109

Ce document a été généré automatiquement le 14 janvier 2023.

Tous droits réservés 


\section{L'Épanchement du conte dans la littérature}

Textes réunis et présentés par Christiane Connan-Pintado, Pascale Auraix-Jonchière et Gilles Béhotéguy, Bordeaux, Presses Universitaires de Bordeaux, coll. " Modernités ", $\mathrm{n}^{\circ}$ 43, 2018, 284 p.

\section{Jean Mainil}

\section{RÉFÉRENCE}

L'Épanchement du conte dans la littérature, textes réunis et présentés par Christiane Connan-Pintado, Pascale Auraix-Jonchière et Gilles Béhotéguy, Bordeaux, Presses Universitaires de Bordeaux, coll. « Modernités », n² 43, 2018, 284 p.

1 Ce volume d'articles riche en analyses et informations a pour but de contribuer à la remédiation d'une carence décrite dans l'«L'Avant-propos» par Christiane ConnanPintado : «Le domaine du conte a passionné toutes les branches des sciences humaines $\mathrm{au}$ cours $\mathrm{du} \mathrm{xx}^{\mathrm{e}}$ siècle, mais force est de constater que les théoriciens de l'intertextualité ne se sont guère souciés de lui et qu'il a pu sembler victime, hors du cercle des spécialistes, d'un certain déficit de légitimité littéraire. » À l'absence de ces analyses, il faut ajouter celle des traductions d'ouvrages en anglais, notamment ceux de Marina Warner. Est à remarquer cependant l'ouvrage, conséquent, de Ute Heidmann co-écrit avec Jean-Michel Adam, Textualité et intertextualité des contes, Perrault, Apulée, La Fontaine, Lhéritier... qui traite de ce sujet en amont des contes de fées de l'Ancien Régime.

On trouvera dans L'Épanchement du conte dans la littérature nombre d'articles sur l'intertextualité du conte de fées de l'Ancien régime, en aval, dans l'œuvre, notamment, d'auteurs aussi différents que Marie NDiaye, Michel Tournier, Kurt Vonnegut, Anne Sexton, et aussi dans des corpus aussi variés que des "auteurs prolétariens ", le(s) conte(s) africain(s), la littérature de jeunesse marocaine, et dans la science-fiction. 
Quelques pistes figurent également qui ouvrent la voie à des réflexions sur "L'épanchement des contes dans l'enseignement de la littérature ».

3 Le corpus rassemblé ici rend justice au conte et à sa nature véritablement universelle et parfois clandestine, et le but visé est atteint : «[...] questionner la présence affichée ou latente des contes patrimoniaux ou du conte comme genre littéraire dans les œuvres contemporaines, ainsi que le dialogue permanent que la littérature et l'expérience littéraire entretiennent avec le domaine des contes, sur le mode de l'innutrition ou de la réappropriation.» («Avant-propos », p. 5) Tout lecteur et toute lectrice passionnés par le conte de fées trouveront ici une source d'inspiration et de découvertes, tant il est vrai que, depuis le $\mathrm{XVII}^{\mathrm{e}}$ siècle, le conte de fées, ses récits et ses figures majeurs participent à notre imaginaire, qu'il s'agisse du monde de la publicité, de l'industrie cinématographique, télévisuelle ou vidéoludique, qu'il s'agisse de contes africains, de récits plus confidentiels ou encore de succès planétaires tels que les œuvres de J. K. Rowling qui trouvent ici aussi leur place. Un des mérites de cet ouvrage est d'avoir ouvert et consolidé de nombreux dialogues intertextuels du conte de fées avec un corpus multilingue, multinational, multisupport (oral, écrit, visuel, etc.) confirmant d'une manière concrète plus qu'en le déclarant simplement, que le conte de fées, par ses "épanchements" analysés dans ce volume, est véritablement universel. Noble - même si elle peut paraître tardive - vengeance d'un genre mineur, bâtard, sans lettres de noblesses classiques, genre adulé par ses premiers lecteurs et ses premières lectrices, mais vilipendé par une critique sourcilleuse du déclin de l'influence classique d'une part et d'autre part de l'influence croissante des femmes dans la sphère littéraire.

Comme le montre bien le présent volume, la littérature, mais également toute l'industrie de la communication, qu'elle soit visuelle, littéraire ou orale, ont été et sont influencées par le conte, ses inoubliables héros et héroïnes qui font partie, parfois sans que nous nous en rendions compte, de notre imaginaire, et donc de notre quotidien. Que l'on appelle cet irrésistible rayonnement du merveilleux dans notre vie un « épanchement », une « irradiation ", une influence, cela tient d'un choix personnel.

\section{AUTEURS}

JEAN MAINIL

UGent, Belgique 